http://dx.doi.org/10.12795/PH.1990.v05.i01.28

\title{
«La Prometeida»: dialéctica y paradigma
}

Adrián Huici

\section{Introducción}

El «Prometeo encadenado», como toda creación artística, no puede reducirse a una única definición o atribuírsele un sólo significado. Antes bien, en esta tragedia particularmente, queda totalmente de manifiesto la multivocidad de la obra literaria. Su extraordinaria riqueza de símbolos e ideas y su hondura religiosa y filosófica obligan a considerarla desde distintos puntos de vista y como una totalidad. No podríamos en ella, como bien dice Aristóteles ${ }^{1}$, quitar ninguno de sus elementos constitutivos, formales o conceptuales, so pena de mutilarla.

Nuestra intención es analizar el «Prometeo encadenado» basándonos en los presupuestos críticos de Gilbert Murray ${ }^{2}$. Es decir, teniendo en cuenta que existe un proceso evolutivo, tanto en la figura de Zeus como en la de Prometeo, el cual se da a través de toda la trilogía.

Considerando lo antedicho, intentaremos ver en «La Prometeida» una dialéctica ascendente, que se da tanto en el plano de lo divino como en el de los mortales, a través de la cual irán surgiendo distintos temas tales como el de la rebeldía, la arbitrariedad

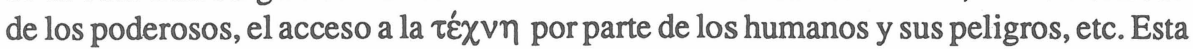
concepción y, principalmente, la noción de evolución moral de los dos grandes agonistas, nos llevarán, inclusive, a exceder los límites de la trilogía en cuestión ya que el pensamiento de Esquilo se proyecta a lo largo de toda su obra conocida. Así, esas ideas básicas, tratadas de diversos modos, afloran en cada una de sus obras y encuentran majestuosa culminación en «La Orestíada».

\footnotetext{
${ }^{1}$ Aristóteles, Poética, (Madrid: Aguilar, 1979).

${ }^{2}$ Murray, G., Esquilo, el creador de la tragedia, (Bs. As. Espasa Calpe, 1955).
} 
Finalmente, sabiendo de la misión educadora que la democracia ateniense asignó a sus poetas, podemos corroborar en toda su obra en general, y en «La Prometeida» en particular, que Esquilo ha ofrecido a su amada Atenas un magnífico paradigma, digno de ser meditado e imitado. Y más aún, que la palabra que el poeta dirigió a sus atenienses de dos mil quinientos años atrás conservan ecos y resonancias que aún pueden ser escuchadas y seguidas por los hombres del siglo XX.

\section{La Trilogía}

Muchos estudiosos de la literatura clásica, entre ellos Albin Lesky ${ }^{3}$, han llegado a considerar la posibilidad de que el «Prometeo encadenado» no pertenezca a Esquilo. El estilo y la forma, que no se corresponden demasiado con el resto del corpus esquíleo $\mathrm{y}$, fundamentalmente, lo alejada que aparece esta tragedia del profundo espíritu religioso que alienta en toda su obra, son las razones en las que se basa Lesky para sostener su aseveración. El más piadoso de los trágicos griegos -afirma- jamás pudo presentarnos a un Zeus como el que aparece en el $\Delta \varepsilon \sigma \mu \omega \dot{\tau} \eta \zeta$, en el que nada vemos de aquel dios grande y poderoso en cuyas manos reposaba la justicia, el derecho y, por ende, la armonía universal.

Otro crítico, Ignacio Granero 4 , sin negar la paternidad esquílea de la pieza, considera que sería equivocado pretender que hay en ella una visión negativa de Zeus, contrapuesta a una valorización de la actitud prometeica. Nada de eso, toda la tragedia apunta -según Granero- a demostrar que el indómito Japétida solamente recibe el merecido castigo que corresponde a cualquier ladrón embaucador, por añadiduda soberbio y sacrílego. A ninguno de estos dos estudiosos se les escapa el hecho de que el «Prometeo encadenado», de pertenecer a Esquilo, no es una obra aislada sino que debería formar parte de una trilogía. Sin embargo, ante la falta de las dos obras restantes y de mayores pruebas al respecto, prefieren atenerse al material conocido.

Contra estas opiniones tenemos la del ya aludido Murray y la de Louis Séchan ${ }^{5}$, quienes aseguran la existencia de la trilogía y, por supuesto, la paternidad de Esquilo. A los efectos del presente trabajo, será ésta última posición la que adoptaremos ya que

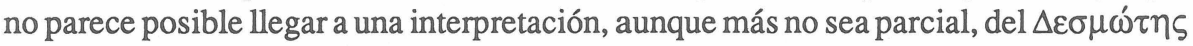
sin tener presente, no sólo las otras dos piezas sino -como ya quedó dicho- la totalidad de la obra conocida de Esquilo. Solamente así podemos atribuir al poeta la visión de un dios despótico y cruel que parece complacerse en el martirio infligido al rebelde titán y a la indefensa Io.

El «Prometeo encadenado» es la primera de las tres piezas y le siguen, en segun-

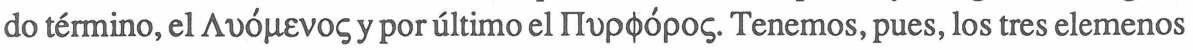

${ }^{3}$ Lesky, A., La tragedia griega, (Barcelona: Labor, 1970).

${ }^{4}$ Esquilo, Prometeo encadenado, prólogo, trad. y notas de Ignacio Granero. (Mendoza, Univ. Nac. de Cuyo, 1964).

${ }^{5}$ Séchan, L., El mito de Prometeo (Bs. As: EUDEBA, 1960). 
que, oponiéndose y complementándose a la vez, irán construyendo esa arquitectura dialéctica que permitirá a ambos agonistas evolucionar hacia una conciencia moral y espiritual superior. Tesis y antítesis serán el $\Delta \varepsilon \sigma \mu \omega ́ \tau \eta \zeta$ y el $\Lambda$ vó $\mu \varepsilon v o \zeta$. En el primero se muestra la posición irreductible del dios y el titán, en el segundo, el perdón y la liberación que permitirán arribar al Пvpфópos, la síntesis que resuelve definitivamente el conflicto. Por este camino arduo y doloroso, el Zeus inflexible del comienzo alcanzará la sabiduría y la capacidad de perdonar. Y Prometeo aprenderá a respetar la autoridad de quien es el padre de todas las cosas y, además, será venerado en Atenas en la que se instituirá una fiesta en su honor. Así también lo entiende Séchan al contestarse esta pregunta:

¿Cómo conciliar esta imagen de un Zeus incontestablemente tiránico con la no menos incontestable piedad de Esquilo? La solución de este problema reside en el hecho de que el $\Delta \varepsilon \sigma \mu \omega ́ \tau \eta \zeta$ no era sino el primer elemento de una trilogía y que ese carácter inicial de Zeus debía transformarse -como también por otra parte el de Prometeo- en el curso de una evolución paralela ${ }^{6}$.

\section{El plano divino: Teomaquia y teodicea}

Habíamos dicho anteriormente que ese proceso de transformación espiritual que lleva a una elevación moral se daba no sólo en el mundo de los dioses sino también en el de los hombres. Siguiendo, entonces, esa gradación jerárquica, nos detendremos primeramente en el nivel superior. Luego descenderemos para observar cómo lo que sucede en las moradas olímpicas, también se da entre los humanos, sirviendo de modelo. Pero además, y esto es destacable, en esta estrecha interacción entre hombres y dioses, los primeros pueden ejercer su influencia sobre estos últimos, contribuyendo también a ese proceso de humanización.

Ante el grandioso enfrentamiento entre Zeus y Prometeo y después de oír terribles amenazas de ver cómo el rayo divino precipita al titán con sus solidarias Oceánides a los profundos abismos, resultaría ocioso explicar el título de «teomaquia». En cuanto al de «teodicea», también surge de la noción de evolución dialéctica sólo que, en este caso, se trata de un «viaje» por el camino del dolor que llevará a ambos contendientes a un nivel de conciencia superior.

Dice Mircea Eliade ${ }^{7}$ que las religiones más evolucionadas son aquellas en que se logra la conciliación de los opuestos: así, por ejemplo, en la figura de Cristo se funden dios y hombre, el nacimiento como mortal a partir de una virgen, la muerte y la resurrección, etc. Hecha esta aclaración, analizaremos ahora las figuras de Zeus y Prometeo, tanto en sus aspectos positivos como negativos, y veremos cómo se llega, también aquí, a esa «coincidentia oppositorum» en la que ambos polos se necesitan y se nutren. Sólo en conjunto podrán transformarse con beneficio tanto para ellos como para la humanidad.

\footnotetext{
${ }^{6}$ Ibid. p. 31.

${ }^{7}$ Eliade, M., La búsqueda, (Bs. As. Megápolis, 1971).
} 
El conflicto que suscita el enfrentamiento entre ambos personajes es bien conocido, especialmente porque Hesíodo se ocupó de ello tanto en la «Teogonía» como en «Los trabajos y los días» ${ }^{8}$. Zeus acaba de derrotar a los titanes e instaurar su nuevo reinado. El soberano, en una de sus primeras determinaciones, piensa destruir la mísera raza de los mortales cuando su reciente alidado, Prometeo, se alista en el bando de los hombres. Esta toma de posición del titán lo lleva a burlar los deseos del Crónida: primero el engaño del buey y, luego, el robo del fuego que permitirá a los hombres el acceso a la $\tau \dot{\varepsilon} \chi \vee \eta$ : «Por Prometeo tienen los hombres todas las artes»9 . La respuesta de Zeus no se hace esperar. Enfurecido, envía a los mortales toda clase de males y encadena a Prometeo a la cima de una desolada montaña. Allí lo encontramos en el Prólogo de nuestra obra y él mismo narrará su historia.

En esta pieza, Prometeo enfoca el conflicto desde su punto de vista y es por ello que su imagen se opone totalmente a la que nos muestra Hesíodo. Si el titán del $\Delta \varepsilon \sigma \mu \omega ́ \tau \eta \zeta \varsigma$ sólo nos habla de las grandes bendiciones que su acción trajo a los humanos y de la arbitrariedad y furia de Zeus, en la «Teogonía» y en «Los trabajos y los días», es su intento de ayudar al hombre, empleando malas artes, el que acarrea a los humanos innúmeras miserias. Así, pues, muchos críticos han rechazado de plano la idea de un Prometeo salvador de la humanidad, de un claro antecedente de Quien luego moriría por el hombre, también crucificado. Sin embargo, y aunque fuera Prometeo causante de tantas calamidades, esto no alcanza a poner a salvo la figura de Zeus. Aunque equivocado, Prometeo quiso ayudar a los hombres. Simplemente, y esto resulta paradójico en virtud de su nombre, no previó los alcances de su acción: «De voluntad erré, de voluntad; no lo negaré. Favoreciendo a los mortales me buscaba trabajos, más no podía imaginarme que con tales suplicios me había de consumir en esta altiva roca» ${ }^{10}$. En cambio, las intenciones de Zeus fueron siempre violentas: primero en su deseo de aniquilar a la raza humana y, luego, en el castigo infligido a su ex-aliado.

Antes de continuar queremos aclarar que, si bien Zeus no aparece nunca en escena, es obvio que ese gran agón que es el «Prometeo encadenado» en particular y «La Prometeida» en general, tiene como únicos contendientes a Zeus por un lado y a Prometeo por el otro. Y sobre la base de lo ya visto, es evidente que el conflicto es demasiado complicado y hondo como para reducirlo a un mero maniqueísmo en el que una parte es todo luz y la otra solamente oscuridad.

\section{Zeus y Prometeo: luces y sombras}

Hemos visto, y no deja de ser cierto, que Prometeo, aún bienintencionado, abre el camino para que el mal entre en el mundo. Sin embargo, no podemos imputarlo como verdadero responsable. Zeus es quien encoleriza y quien castiga. Si Prometeo fuera

\footnotetext{
${ }^{8}$ Hesíodo, Teogonía. Los trabajos y los días (Bs. As. C.E.A.L., 1969).

${ }^{9}$ Esquilo, Tragedias, trad. J. Alemany-Balufer (Bs. As. Losada, 1976), Vs. 506-507. Todas las citas se harán por esta edición.

${ }^{10} \mathrm{Ibid}$. vv. 265 y ss.
} 
totalmente culpable, entonces sólo él debía haber pagado por su irreverencia. Pero el olímpico, con ciego enojo, descarga también su furia sobre la humanidad a la que, por otra parte, ya quería destruir. Todos deben padecer, entonces. Esta actitud está viciada de una innegable arbitrariedad y la «psicosis bélica» -como la llama Granero- que aún sufre Zeus a causa de sus recientes luchas no es, en modo alguno, circunstancia atenuante para su crueldad. Podríamos pensar que la violencia ejercida contra Prometeo está justificada: la falta del titán condiciona a Zeus para que actúe injustamente. Pero la patética historia de Io desmiente lo antedicho y demuestra que el dios es cruel con todos, aún con quienes se supone que ama. Dice García Gual:

Hay una contraposición entre Io y Prometeo: ella es la víctima inocente de los designios personales y apasionados de Zeus al margen de la justicia, mientras que Prometeo es un delincuente rebelde y altivo frente a los designios de este Tirano cuya justicia se rige por un arbitrario poder personal, según cree Prometeo. De alguna manera, tanto la pasión de Prometeo como la de Io coinciden en levantar una acusación de crueldad contra el Soberano Zeus ${ }^{11}$.

Tenemos, entonces, a un dios arbitrario y cruel en demasía. Ni rastros encontramos en él de aquel padre justo y comprensivo que otorga la gracia de su perdón a Orestes. Es lícito, pues, sospechar que no pertenezca a Esquilo esta imagen de la divinidad suprema... Pero, según hemos dicho, Zeus evolucionará; y así podremos afirmar que este dios y aquel a quien el coro del «Agamenon» honra con este himno son uno y el mismo:

¡Oh Zeus, quien quiera que tu seas, yo te invoco con este nombre, si con él te agrada ser invocado! Porque bien considerado todo en mi mente..., no hallaré en verdad quien con Zeus pueda compararse... Más quien de corazón celebre a Zeus con jubiloso himno de triunfo, llegará al colmo de la sabia prudencia ${ }^{11 b i s}$.

La figura del Crónida posee, en estado germinal todavía, toda la majestad que luego le otorgará el poeta. Y esta faceta negativa agiganta más aún su condición ya que, a partir de una posición de crueldad e injusticia, el dios será capaz de vencerse a sí mismo, aprendiendo de sus errores para alcanzar la $\Sigma \omega \phi \rho 0 \sigma v ́ v \eta$ y de sobreponerse al pecado: «peca et peca fortiter».

Tras esta imagen del dios se perfilan nítidamente las grandes cuestiones que inquietaban a Esquilo: el problema de la justicia, el de la «moira», es decir el reparto equitativo de bienes y males, y la precariedad de las cosas humanas, etc. Estas son preguntas que ya se habían formulado Solón, y aún antes Hesíodo. Preguntas acuciantes que llevan al poeta a lanzar, en boca de su héroe, esta protesta apasionada: «... juzgo por mejor servir a esta roca que no ser dócil mensajero de Zeus, tu padre. Así es razón que con ultrajes responda a quien me ultraja» ${ }^{12}$. No resulta fácil creer que sea el piadoso autor de «Las

${ }^{11}$ García Gual, C. Prometeo: mito y Tragedia (Madrid, Hiperión, 1979). P., 113.

11 bis Ibid. vv. 160 y ss.

${ }^{12}$ Ibid. vv. 968 y ss. 
Euménides» quien hable de esta manera. Sin embargo, la dolorosa duda y la angustia dejarán paso a una fe monolítica. El pensamiento de Esquilo, al igual que el de Zeus, evolucionará. Así como la sabiduría reemplazará a la violencia en el ánimo del Padre, esa situación de rebeldía y escepticismo inicial será superada por el propio poeta y se transformará en inconmovible fe. El dios y el hombre, en un mismo impulso ascendente, se elevan guiados por el más sabio de los maestros: el dolor. Y nuevamente volvemos al coro del «Agamenón»:

A aquel dios que encamina a los mortales a la sabiduría y dispuso que en el dolor se hiciesen señores de la ciencia... Don del dios que sentado en augusto trono, rige con diestra vigorosa la nave de nuestros destinos ${ }^{13}$.

Zeus ha dispuesto que los hombres aprendan por el áspero camino del sufrimiento, pero él mismo es el primero en someterse a esa ley. Más adelante volveremos sobre este «democrático» proceder que, proviniendo de Esquilo, es profundamente significativo.

Es bien sabido que para la mentalidad griega era inconcebible la idea de una creación «ex nihilo». Todo tiene su origen y su explicación: de Gea nace Urano y a éste le sucederá Cronos. Zeus será el tercero en esta sucesión divina, aunque no por ello menos violenta. La marcha del universo es un constante cambio simbolizado en esos dioses que, uno tras otro, van siendo destronados. Zeus mismo es el resultado de ese plan. Con la violencia se adueñó del trono y por ella, algún día, puede caer. Pero en este punto aparece un fenómeno distinto: el Crónida posee una nueva arma, el pensamiento. Esta facultad permitirá que aquella evolución producida a escala cósmica, se dé también en el ánimo del dios. Aunque con el pensar no basta. Es cierto que le ha servido para derrotar a sus enemigos y erigirse en el amo absoluto. Pero hasta aquí sólo tenemos a un nuevo tirano -en el sentido moderno de la palabra-, más inteligente pero igualmente déspota.

Para que Zeus cambie, para que se desprenda de esa carga de violencia ciega y de arbitrariedad, es necesario que alguien lo abofetee en pleno rostro. Alguien debe demostrarle que, no por ser el amo, tiene derecho a aniquilar a sus súbditos a su antojo, o a enviarles todo tipo de calamidades por el simple placer de ejercer su omnipotencia. Alguien debe gritarle que la justicia es mejor que la venganza, la comprensión que la fuerza pura y el perdón mejor que el castigo irracional. El Crónida debe comprender que su reinado peligrará en tanto no cambie su manera de ejercer el poder.

Pero quien se atreva a enfrentar al señor debe poseer mucho temple y coraje. Debe ser alquien que, aun clavado a una roca, sumido en eterna tortura, tenga la fuerza de gritar al olímpico que nunca se doblegará ante su cólera indiscriminada. Y todavía más: ha de tener la suficiente desmesura como para, aunque sumido en esa triste condición, poder proferir terribles amenazas: «Y con todo ello ese Zeus, aun cuando de ánimo tan arrogante, todavía alguna vez ha de ser humilde... Cuando se estrelle contra

${ }^{13}$ Ibid. vv. 176 y ss. 
su desgracia, entonces aprenderá cuánto va de imperar a ser esclavo» ${ }^{14}$. He aquí la gran misión de Prometeo: combatir al déspota; levantarse, como poderosa antítesis, para

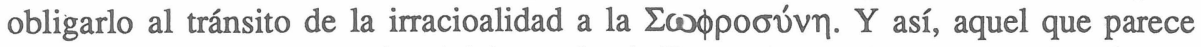
regocijarse ante la perspectiva del derrumbe de Zeus, al forzarlo a cambiar de métodos e impulsarlo hacia la sabiduría, que es justicia y perdón, no hace sino colaborar en la consolidación definitiva de su reinado. ¿Quién iba a querer derrocar al que, infinitamente poderoso, gobierna con el derecho en sus manos?

Ya habíamos señalado que los agonistas se nutren y complementan. Zeus necesita quien le resista. Zeus necesita a Prometeo, vociferando en la roca, y no al complaciente Océano, siempre dispuesto a adaptarse a la modalidad del nuevo gobernante. No creo que, como dice García Gual, Océano sea «... un consejero un tanto bobalicón que no advierte la dureza del enfrentamiento entre el tirano y el rebelde, ni la ferocidad del odio y la violencia en la lucha del Poder ${ }^{14}$ bis. Antes bien, este viejo cortesano actúa de manera acomodaticia precisamente porque conoce muy bien la dureza de la que es capaz Zeus para defender su trono. Podríamos decir que Océano es el verdadero enemigo, del dios y, por lo tanto, de la humanidad. Su servil aceptación de la voluntad del amo jamás servirá de estímulo para aquella evolución a la que ya hemos aludido. Por el contrario, la actitud de Océano sólo sirve para incitar a Jove a exacerbar más aún su primitiva manera de gobernar: «Reconócete, y pues que hay nuevo tirano entre los dioses, muda tú también de proceder ${ }^{15}$. Con esa forma de pensar y proceder no es posible esa corriente que, yendo de una a otra posición, permite el ascenso o la transformación que debe cristalizar en fecunda síntesis.

Hasta aquí hemos observado algunos de los aspectos negativos del dios y también notamos su gran virtud: la flexibilidad de pensamiento. No se agota aquí el análisis de la divinidad, pero queremos detenernos un momento en quien provocó, con rebeldía propia del titán que era, esa metamorfosis en el ánimo de Zeus. Y ese efecto producido es justamente la principal virtud que debemos señalar a Prometeo. Es la rebeldía, entonces, su gran mérito. Mérito de doble filo porque cualquier exceso en él conduce, inevitablemente, a la «hybris»: a la desmesura y la soberbia. Es por ello que muchos críticos han visto en el suplicio de Prometeo el justo castigo a esa desmesura. Pero, ¿cómo no ser desmesurado cuando se trata de enfrentar a quien le está dado el dominio del rayo?

Prometeo y Zeus tienen en común el don del pensamiento: la inteligencia que permite prever el porvenir y que nos pone a salvo de abstrusos dogmatismos. La facultad que imprime a las ideas vivificante movimiento. Movimiento que, poco a poco, nos acerca a la verdad ya que «detenerse es equivocarse». Para Zeus, pensar es aprender a ceder, reconocerse falible y cambiar; para Prometeo es previsión que lo lleva a alinearse junto a Zeus porque comprende que los viejos titanes, símbolo de la pura fuerza, ya no tendrán lugar en el mundo. Pero el Japétida es llamado «amigo del hombre», y por ello mismo desea que los mortales también gocen de ese don. Por ello

${ }^{14} \mathrm{Ibid}$. Vs. 925 y ss.

14 bis García Gual, C., op. cit. p. 117.

${ }^{15}$ Ibid. vs. 310 y ss. 
el robo del fuego y la enseñanza de «todas las artes». Sobre este punto vemos que Granero, en su visión siempre desfavorable, observa que los beneficios otorgados a los mortales y de los que tanto se ufana Prometeo, no dejan de ser bienes materiales o utilitarios. Nada que conduzca a la elevación espiritual.

En principio esa aseveración es correcta, pero creemos que incompleta. Es cierto

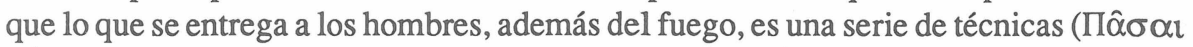
T'́ $\chi v \propto \imath)$ para aplicar a la vida diaria y mejorarla materialmente. La arquitectura, el arte de curar enfermedades, la metalurgia, la previsión de lo porvenir, la geometría, son en cierta manera modos de actuar o de hacer..., pero están indisolublemente unidos a la esfera del espíritu y del intelecto. Goethe, con la intuición que sólo poseen los grandes, acuñó la frase: «En el principio no estaba el Verbo sino el Hecho». Más tarde, en manos de William James, este pensamiento se transformaría en enunciado científico: «... toda conciencia es motriz. Sin movimiento no hay vida y sin acción no hay pensamiento» ${ }^{16}$. Podríamos agregar: «sin pensamiento no hay evolución moral ni justicia». No era simplemente materia lo que se entregó al hombre. Esa llama sagrada, robada en una débil caña, es el símbolo del espíritu humano en su perpetuo anhelo de borrar tinieblas. También Séchan es de esta opinión:

Al domesticar el fuego, al amansar la llama, el ser hasta entonces tan desguarnecido, adquiría un tesoro tanto más inestimable cuanto que no quedaría en modo alguno reducido al orden puramente material; porque el fuego, «elemento vital», es también espíritu sublime, creador de civilización moral ${ }^{17}$.

\section{La desedenización}

Conforme lo hasta aquí estudiado, podemos afirmar que la figura de Prometeo aparece ubicada en un nivel intermedio entre dioses y hombres. Su influencia se ejerce tanto hacia el plano superior como hacia el inferior. Conocemos los efectos beneficiosos que en cada una de esas esferas se producen por su causa. Pero también hemos de ver cómo el progreso del mundo inferior no agrada al superior y enfurece a ese Zeus todavía primitivo. No es patrimonio de la mitología griega esa tendencia de los dioses a evitar y castigar el surgimiento de la conciencia en los humanos. La caída de Adán y Eva y su expulsión del Paraíso Terrenal no cuentan otra cosa. En el Edén el hombre no ha emergido aún de la naturaleza y «se siente identificado con el mundo de los animales y de los árboles, y trata de lograr la unidad formando parte del reino natural» ${ }^{18}$. Estas palabras de E. Fromm hallan un claro eco en las afirmaciones de Prometeo: «Debajo de la tierra habitaban, a modo de ágiles hormigas en lo más escondido de los antros donde no llega la luz» -no sólo luz física era lo que faltaba- «No había para ellos signo cierto

\footnotetext{
${ }^{16}$ Cit. por Mira y López, E. El Pensamiento, (Bs. As. Kapelusz, 1966), p. 64.

${ }^{17}$ Séchan, L., ob. cit, p. 7.

${ }^{18}$ Fromm, E. El arte de amar, (Bs. As. Paidós, 1971), p. 79.
} 
ni del invierno, ni de la florida primavera, ni del verano abundoso en frutos. Todo lo hacían sin tino... ${ }^{19}$. Se hace innecesario comentar este fragmento: el hombre lleva una vida casi animal -como hormigas- sumido en la ignorancia, tanto del mundo circundante como de sí mismo.

Es verdad que el Paraíso representaba para Adán y Eva una situación perfecta. Ambos transitaban por una blanda semiinconsciencia, en la que no era necesario esfuerzo alguno por sobrevivir, sin angustias ni grandes problemas..., exactamente como cualquier animal. Es por ello que, tanto el árbol del conocimiento como la chispa divina de Prometeo, no representan otra cosa más que el acceso a un mundo no tan perfecto, es cierto, pero más humano. No es casual que a los dioses disguste este ascenso de la raza de «un sólo día». Si hasta ese momento los hombres eran míseras hormigas, ahora, con esa nueva facultad podrían intentar emular a sus creadores. Eso mismo temen los dioses mayas de sus criaturas: «No está bien lo que dicen nuestros construidos. Lo conocen todo, lo grande, lo pequeño. Deshaganos un poco lo que quisimos que fuesen ${ }^{20}$. Eso mismo murmura la serpiente al oído de Eva: «Más sabe Dios que el día que comieseis de él, serán abiertos vuestros ojos y sereis como dioses...» ${ }^{21}$.

Esta visión de un dios celoso de su creación responde a la concepción de la divinidad primitiva y violenta. Tan violenta que intenta aniquilar a sus hijos: «Y arrepintióse Jehová de haber hecho al hombre y pesole en el corazón: raeré a los hombres que he creado de la faz de la tierra...»22.

También Zeus quiere destruir a los humanos aunque, según se dice, con el fin de crear seres superiores. Y en este punto se agiganta más aún la dimensión humanitaria de Prometeo. El titán no admite el sacrificio de sus protegidos, por miserables que sean, en aras de una raza superior. Prometeo no quiere superhombres, sólo hombres laboriosos que construyan su porvenir en una dimensión siempre humana. A nadie escapará, seguramente, la resonancia que tiene para el hombre de nuestros días esta oposición entre hombres comunes y raza superior.

Abstrayéndonos de la historia particular, en el enfrentamiento del Zeus destructor contra un Prometeo lleno de clemencia, podemos ver claramente las diferencias que existen entre lo que Fromm llama religión autoritaria y religión humanitaria. La primera conlleva la idea de sumisión y obediencia ciegas, no por las cualidades morales de la divinidad, sino, simplemente, por el poder que ésta ejerce. Dentro de esta concepción, la divinidad es vista como omnipotente y omnisciente y el hombre como un ser impotente e insignificante. En cambio:

La finalidad del hombre en la religión humanista es lograr la mayor fuerza, no la mayor impotencia; la virtud es la autorrealización, no el autodesprecio... Cuando las

\footnotetext{
19 Esquilo, ob. cit. vs. 452 y ss.

${ }^{20}$ Anónimo, Popol Vuh, (Bs. As. Losada, 1981), p. 91.

${ }^{21} \mathrm{Gen}, 3.5$.

22 Gen, 5. 6.
} 
religiones humanitarias son teístas, Dios es el símbolo de los poderes del hombre y no un símbolo de fuerza y dominación que tienen poder sobre el hombre ${ }^{23}$.

\section{La desobediencia}

Al encarnar Prometeo el modelo de religión humanista, no sorprende, entonces, que la desobediencia a una deidad cruel se cuente entre una de sus peculiaridades más notables. Podríamos decir, inclusive, que es una de sus mayores virtudes. Pero, para ello, es necesario distinguir, como hace Fromm ${ }^{24}$, entre la desobediencia positiva y la negativa. La rebeldía por la rebeldía misma no conduce a nada, o mejor dicho, conduce a la destrucción, tanto del rebelde como de su mundo. Tampoco la obediencia ciega e irreflexiva es beneficiosa. Por el contrario, sólo sirve para intensificar los defectos de quien ejerce el poder: ya lo hemos notado en la persona de Océano. Entendemos positivas a la rebeldía racional, que se levanta contra la autoridad ciega y despótica, y a la obediencia basada en la confianza mutua, establecida entre quien manda y quien obedece, y en la fe cimentada en la bondad y la justicia, provenga ésta del maestro, del rey o de Dios.

Prometeo no tolera la arbitrariedad ni la injusticia de los poderosos, no admite la ingratitud de quien recibiera su ayuda, y menos aún, comparte la idea de destruir para crear algo superior: prefiere educar y guiar a reemplazar destruyendo. Por ello se rebela y asume todos los riesgos que ello trae consigo.

La aceptación pasiva de la autoridad significa también, pertenecer al rebaño y por tanto, seguridad y protección. Para oponerse al amo se requiere coraje -como dice Fromm- «coraje de estar solos, errar y pecar» ${ }^{25}$. Quien se rebela contra un orden establecido, injusto o cruel, se expone a la furia del poderoso y al aislamiento de su mundo. ¿Qué mejor símbolo de esta situación que la dura roca escita donde Prometeo paga su osadía con dolor y soledad? El mérito del titán reside, entonces, en que su resistencia a Zeus terminará por imponer al Crónida la toma de una actitud nueva, más acorde con el dios de la religión humanista.

De todas maneras, no debemos ver en el proceder de Zeus solamente crueldad y furia sin fundamento alguno. Jaeger insinúa en su Paideia ${ }^{26}$ la posibilidad de que en Prometeo se castigue la desaprensión de haber entregado a unos seres irresponsables, como son los mortales, unos medios técnicos que, mal utilizados, pueden traer funestas consecuencias. El titán no cree que sus dones sean peligrosos: «La industria puede menos que el Hado.... ${ }^{27}$; sin embargo, en el espíritu griego existió siempre la idea de que había ciertos límites que el hombre no debía transponer. Eso mismo nos enseña el coro

\footnotetext{
${ }^{23}$ Fromm, E. Psicoanálisis y religión, (Bs. As., Psique, 1971), p. 57.

${ }^{24}$ Fromm, E. La desobediencia, (Bs. As. Paidós, 1984).

25 Ob. cit. p. 15.

${ }^{26}$ Jaeger, W. Paideia, (México, F.C.E., 1978).

${ }^{27}$ Esquilo, ob. cit. V. 514.
} 
de Antígona cuando habla de los portentos humanos cuya «sabia inventiva ha logrado conocimientos más allá de lo esperable y a veces los encamina hacia el mal... ${ }^{28}$. Y si alguna duda teníamos sobre la actualidad de lo griego, detengámonos en estas palabras escritas por Karl Jaspers en 1.958: «Las sucesivas realizaciones del hombre suscitan una y otra vez el mismo interrogante: ¿qué destino dar a esas creaciones técnicas? ¿Logrará dominarlas? ¿O deberá subordinarse a ellas?» ${ }^{29}$.

\section{El plano humano: Su interacción con el arquetipo divino}

Según Séchan, el mismo Cicerón consideraba a Esquilo «no solum poeta sed etiam Pythagoreus» ${ }^{30}$. Si tenemos en cuenta que entre las artes civilizadoras que se entregan al hombre, Esquilo incluye a la geometría, podemos dar cierta validez a aquella aseveración. Pero, además, durante todo el «Prometeo encadenado» es posible detectar una jerarquización impuesta a la organización cósmica, característica de las enseñanzas del maestro de Samos. Se puede ver en la escala que va de dioses a hombres una relación de macrocosmos a microcosmos (términos éstos -según afirman-creados por Pitágoras).

Se ha notado ya que en la esfera de la divinidad, por obra de Prometeo y de la inteligencia de Zeus, se produce la evolución desde un instintivo primitivismo a una conciencia moral superior. Otro tanto sucede en el mundo de los mortales. Por obra del Japétida, los humanos adquieren, ellos como Zeus, la facultad del pensamiento creativo. Gracias a este don, la humanidad puede superar una etapa casi animal para convertirse en la dominadora de casi todas las fuerzas hostiles de su entorno.

Lo que sucede en el plano superior se refleja también en el inferior. Y el gozne sobre el que giran estos dos mundos es, justamente, el titán encadenado que sirve de vínculo entre ambos y sobre ambos ejerce su influjo. Esta vinculación de lo divino con lo humano trasciende el plano de la comunidad y alcanza al individuo. El progreso moral de la divinidad se repite, no sólo en la polis, sino también, y es deseable que así ocurra, en cada uno de sus integrantes.

Vemos entonces que, en este paralelismo, con el pensamiento alcanza Zeus la sofrosyne y los hombres el dominio de la naturaleza y de sí mismos. Pero la razón no basta. El Crónida ha establecido que el dolor será el mejor maestro en este largo aprendizaje. Él mismo se somete a esa norma que luego será aplicada a los humanos. Dioses y hombres, por igual, obedecen a las mismas leyes. Evidentemente, con esta actitud de Zeus, Esquilo no está sino consagrando a la naciente democracia.

El camino que va de los dioses a los hombres tiene, en el poeta, vías de ida y vuelta. Quiere decir esto que también le es dado al hombre influir en la divinidad. Y cuando aquí hablamos de «hombre», nos referimos concretamente a Esquilo. El poeta,

${ }^{28}$ Sófocles, Antígona (Barcelona, Bruguera, 1982).

${ }^{29}$ Jaspers, K., La bomba atómica y el futuro de la humanidad (Bs. As. Cía Fabril Editora, 1958), p. 277.

${ }^{30}$ Séchan, L. ob. cit. p. 16. 
preocupado siempre por los grandes problemas de la justicia y las fatigas humanas, se niega a aceptar unos dioses crueles e indiferentes. Pero su obra no queda en el mero rechazo. Muy por el contrario, con su potencia creadora mediante, el viejo héroe de Maratón se abocó a la grandiosa tarea de recomponer su fe mostrándosnos que los dioses, como los hombres, pueden aprender de sus errores y cambiar. Así, aquella dialéctica que, según señalábamos, se daba entre las posiciones de Zeus y Prometeo, se repite aquí, entre lo divino y lo humano. Ambas esferas, en principio enfrentadas y disociadas, terminan plasmándose en una síntesis de la que la armonía universal es su reflejo. Goethe también siente esa participación de lo superior en lo inferior y viceversa y lo dice bellamente: «Si el ojo puede ver el sol es porque tiene en sí mismo algo de solar».

Con este esfuerzo espiritual, Esquilo concede al hombre un papel fundamental, dignificándolo hasta darle participación en el orden cósmico: «Para que los dioses mejoren, debemos mejorar primero a los hombres». Nunca más pertinente la sentencia de Jenófanes.

No es en «La Prometeida», únicamente, donde Esquilo trata este problema del progreso espiritual de hombres y dioses. También «La Orestíada» nos habla del mismo tema. Y también aquí se llega a una elevación moral. Zeus perdonará a Orestes y los hombres ya no lavarán sangre con sangre sino que se someterán al tribunal del Areópago. No es casual que ambas trilogías terminen con la institución de un nuevo culto. A las Euménides en «La Orestíada» y en «La Prometeida», al Пvpфópos.

A pesar de la instauración, en el Olimpo, de un Zeus más justo y benéfico, no se escapaba, seguramente, a Esquilo que la iniquidad y el sufrimiento seguían imperando en el mundo. Pero el poeta no ve ahora maldad ni cólera irracional. Todo lo que sucede forma parte del plan divino, sólo que el hombre, con sus limitaciones, no puede comprenderlo. Por otra parte, intentarlo sería un acto de soberbia. Además, Esquilo es el más religioso de los trágicos y no puede caer en un deseo de racionalización que no haría sino atentar contra su fe. Al respecto, y comentado las ideas religiosas de Nietszche, dice Massuh:

La razón señala el momento de decadencia de una religión por lo mismo que implica una subordinación del mito a sus leyes y una supresión, por lo tanto, de su libertad imaginativa. Una religión que se hace rígida, deviene ortodoxia y se convierten en dogma, ha sucumbido a la razón y atenta contra sí misma ${ }^{31}$.

Mucho mejor todavía lo dice el poeta por intermedio del coro de «Las Suplicantes»:

Lo que la mente de Zeus tiene decretado que suceda jamás se tuerce ni se frustra, sino que llega a su fin por aquellos caminos dilatados del pensamiento divino, envueltos en espesas tinieblas, donde el ojo del hombre no puede nunca penetrar ${ }^{32}$.

${ }^{31}$ Massuh, V. Nietszche y el fin de la religión, (Bs. As. Sudamericana, 1976), p. 44.

${ }^{32}$ Esquilo, ob. cit. Vs. 65 y ss. 
Así vemos que Esquilo en ningún momento quiere entender, simplemente construye su idea de Dios y deposita en ella toda su fe con inconmovible confianza. Nuevamente la palabra del poeta resuena desde la lejanía del siglo $\mathrm{V}$ y aún ahora podemos escucharla con nitidez. Veamos, si no, qué nos dice el psicólogo Víctor Frankl, creador de la logoterapia, respecto a la imposibilidad de comprender la marcha del universo:

Exactamente del mismo modo que un animal no puede, trascendiendo su medio, llegar a comprender nunca el mundo de los hombres, que está por encima de él, el hombre no puede llegar nunca a comprender qué es lo que está por encima de su mundo propio; puede a lo sumo llegar a vislumbrarlo por medio de la $\mathrm{fe}^{33}$.

No es casual que sobre la obra de este hombre, que ha incorporado al psicoanálisis nociones tales como «inconsciente espiritual», «dolon» y «amor», sople el tenue espíritu de lo clásico humanizando una ciencia a veces un tanto alejada del fenómeno humano en sí.

En varias ocasiones señalamos la estrecha vinculación existente entre el plano superior y el humano, y vimos cómo se influyen mutuamente. Esta idea posee connotaciones religiosas muy profundas, comunes a toda la humanidad y ampliamente estudiadas por M. Eliade. Para el pensamiento mítico, dice este autor»,

... el objeto hecho por la industria del hombre, no halla su realidad, su identidad, sino en la medida en que participan en una realidad trascendente, sino en la medida en que renueva una acción primordial ${ }^{34}$.

Los hechos y hazañas de dioses y antepasados, acaecidos $a b$ origine funcionan como modelos que, repetidos e imitados ritualmente, permiten la recuperación de aquel tiempo originario, real. El hombre debe, por lo tanto, imitar aquellos arquetipos o modelos sagrados, instituidos por los dioses. De esta manera, las obras humanas cuentan con la sanción divina, se sacralizan. De esto nos habla San Agustín al referirse a las dos ciudades y, siempre en la tradición judeo-cristiana, era común la creencia de que la Jerusalem terrena era la copia exacta de igual ciudad celestial.

Sobre la base de estas ideas, podemos afirmar que algo similar perseguía Esquilo con su obra. En «La Orestíada» se evidencia la intención de demostrar que ese tribunal, recientemente constituido, cuenta con el consentimiento y el beneplácito de los dioses. En «La Prometeida» puede apreciarse el deseo de demostrar que la democracia ateniense no solamente cuenta con la benévola mirada de los dioses, sino que se trata de la repetición, a nivel terreno, de un suceso cósmico. Si la divinidad transitó desde la fuerza ciega y arbitraria hacie estadios superiores, otro tanto sucederá en el mundo de los hombres. La vieja y cruel tiranía, el dominio y la iniquidad del poderoso, dejarán lugar, luego de un doloroso camino, a un sistema de gobierno y de vida

${ }^{33}$ Frankl, V., Psicoanálisis y existencialismo, (México, F.C.E. 1978), p. 67.

${ }^{34}$ Eliade, M. El mito del eterno retorno, (Madrid, Alianza, 1972), p. 45. 
más justo y benéfico. La naciente democracia, al contar con esta sanción de los Inmortales, se sacraliza y se carga de hondas connotaciones religiosas de la mano de Esquilo, su máximo sacerdote.

\section{Conclusión}

Muchas cosas nos ha dicho Esquilo en su tragedia. Nos ha hablado, por ejemplo, del sufrimiento. Y si, en principio, su presencia en el mundo puso angustia en su corazón, finalmente el poeta termina cantando a ese dolor que proviene de Zeus. El Crónida nos lo ha enviado para que, a través de él, nos hagamos más sabios y alcancemos la medida exacta de lo humano. Para ello nos brinda su ejemplo. Nada es azar en el cosmos organizado por su voluntad, y aunque no siempre comprendamos la razón de nuestros sufrimientos, debemos confiar en que, en la mente de Zeus, todo encuentra su sentido último. A este respecto, García Gual, piensa que: «El dolor, el escandaloso dolor podría tener, a veces al menos, un sentido, si fuera un paso hacia la sabiduría...». Y culmina su reflexión planteándose los mismos y sugerentes interrogantes de Denniston y Page acerca del pathei mathos «i... es posible que él [Esquilo] quisiera indicar algo más elevado -por ejemplo, que los sufrimientos sobre la tierra están impuestos por la divinidad con la función de refinar y purificar el carácter humano? ¿Que la vida es un sendero a través de la tribulación hacia la perfección...? (...) ¿Que el castigo lo inflige Zeus no en ejercicio de la venganza, sino para la instrucción y perfeccionamiento del pecador?» ${ }^{35}$.

También se ha resaltado la misión educadora de Esquilo. Esta obra no hace más que confirmarlo. Seguramente sus contemporáneos, luego de asistir a la representación de «La Prometeida», abandonaron el teatro con la íntima convicción de que su democracia era mucho más que una nueva forma de gobernarse: se trataba de una manera distinta y más humana de entender el mundo, tanto el de los hombres como el de los dioses. Este es el paradigma que ofrece a su pueblo confiando en que el mejor camino es imitarlo.

Todas estas ideas esquíleas se cimentan en la fe cierta de que la divinidad, cruel y dura en los comienzos, puede transformarse para dar lugar a una religión más benévola y -para decirlo con Fromm- más humanista.

En este ascenso dialéctico juega su papel esencial la figura de Prometeo. Sólo su rebeldía será capaz de obligar a Zeus a un replanteo de su manera de gobernar el mundo. La grandiosa imagen del titán clavado en la dura piedra es el más conmovedor ejemplo de la inclaudicable lucha por una vida mejor.

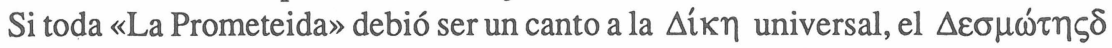
en particular, es sin duda, una exaltación de la rebeldía y la desobediencia. Pero de aquella que se opone a la injusticia en pos de un ideal superior. Por ello creemos que acierta plenamente el psicólogo Rollo May cuando dice:

${ }^{35}$ García Gual, C., ob. cit. p. 160. 
Aquellos a los que llamamos santos se rebelaron contra una forma anticuada e inadecuada de Dios basándose en el nuevo concepto de divinidad que tenían. Las enseñanzas que los llevaron a la muerte elevaron el nivel espiritual y ético de las sociedades a las que pertenecían. Se dieron cuenta de que Zeus, el celoso dios del Monte Olimpo, ya no servía más. Por eso Prometeo abogó por una religión de la compasión. Se rebelaron contra Jehová, el primitivo dios tribal que se deleitaba con la muerte de miles de filisteos. En su lugar llegaron las visiones de Amón, de Jeremías e Isaías, que preconizaban el dios del amor y la justicia. Su rebelión fue motivada por una nueva percepción del significado de piedad. Se rebelaron como tan bellamente lo ha afirmado Paul Tilich, contra Dios en nombre del Dios que trasciende a Dios ${ }^{36}$.

\section{Bibliografía}

Aristóteles, Poética, (Madrid, Aguilar, 1979).

Eliade, Mircea, El mito del eterno retorno, (Madrid, Alianza, 1978).

Eliade Mircea, La búsqueda, (Bs. As., Megápolis, 1971).

Frankl, Víctor, Psicoanálisis y existencialismo, (México, F.C.E., 1978).

Fromm, Erich, El arte de amar, (Bs. As. Paidós, 1.977).

Fromm, Erich, Psicoanálisis y religión, (Bs. As. Psique, 1971).

Fromm, Erich, Sobre la desobediencia, (Bs. As. Paidós, 1984).

García Gual, Carlos, Prometeo: mito y tragedia, (Madrid, Peralta ediciones-Libros Hiperión, 1979).

Granero, Ignacio, en Prometeo encadenado (prólogo, traducción y notas), Mendoza, Univ. Nac. de Cuyo, 1964.

Hesíodo. Teogonía-Los trabajos y los días-El escudo, (Bs. As. C.E.A.L., 1969).

Jaeger, Werner, Paideia, (México, F.C.E., 1978).

Jaspers, Karl. La bomba atómica y el futuro de la humanidad, (Bs. As., Cía Fabril Editora, 1958).

Massuh, Víctor. Nietszche y el fin de la religión, (Bs. As. Sudamericana, 1976).

Mira y López, Emilio. El pensamiento, (Bs. As. Kapelusz, 1966).

Murray Gilbert. Esquilo, el creador de la tragedia, (Bs. As. Espasa Calpe, 1955).

May, Rollo. La valentía de crear. (Bs. As. Emecé, 1977).

Séchan, Louis. El mito de Prometeo, (Bs. As. Eudeba, 1960).

Sófocles. Antígona, (Barcelona, Bruguera, 1976).

${ }^{36}$ May. R., La valentía de crear (Bs. As. Emece, 1977), p. 50. 
